\title{
NOTE ON TRANSCRIPTION OF YIDDISH WORDS
}

Yiddish words in this book are transcribed according to the system developed by the Yídisher Visnsháftlekher Institút (YIVO). Most Yiddish words are accented on the next-to-last (penultimate) syllable. When the accent falls elsewhere, this is indicated by an acute accent over the stressed syllable, e.g. éyverl, gezúnt. See note 4 to Chapter 1 for more details. 

BLESSINGS, CURSES, HOPES, AND FEARS 
